\title{
DESDOBRAMENTOS CLÍNICOS DAS PRÁTICAS DE OBSERVAÇÃO PSICANALÍTICAS DA RELAÇÃO MÃE BEBÊ NO CONTEXTO BRASILEIRO
}

\author{
Camila Rippi Moreno, Jorge Luís Ferreira Abrão
}

Universidade Estadual Paulista - FCL/UNESP. Curso de Psicologia, Assis - SP. Pesquisa Financiada pela FAPESP ( $\mathrm{n}$ processo: 2012/22136-9).

\section{RESUMO}

Os trabalhos psicanalíticos desenvolvidos na Europa a partir da década 1950 sobre a observação e intervenção da relação mãe e bebê tiveram influência no Brasil. O presente trabalho tem por objetivo compreender, a repercussão que os diferentes modelos psicanalíticos dedicados a observação e intervenção da relação pais-bebê exerceram junto a psicanálise brasileira. Valendose de um método histórico, foi realizado o levantamento da produção de artigos nacionais sobre a observação e intervenção da relação mãe e bebê na base de dados BVS Psi, nas duas últimas décadas. Os resultados indicam a existência de 42 artigos que foram analisados e delimitados em 4 categorias: Estudos teóricos epistemológicos, Variações do método Esther Bick, Práticas de Intervenção na relação mãe e bebê na clínica ampliada e Pesquisas sobre características da relação mãe bebê. Conclui-se que os trabalhos relativos a relação mãe-bebê desenvolvidos na Europa tiveram repercussão na psicanálise brasileira, influenciando, sobretudo, pesquisas e práticas institucionais em diferentes contextos.

Palavras-chave: Psicanálise, Relação mãe e bebê, História, Intervenção, Observação.

\section{CLINICAL REPERCUSSION OF PSYCHOANALYTICS OBSERVATION PRATICS OF MOTHER BABY RELATIONSHIP AT BRAZILIAN CONTEXT}

\begin{abstract}
The psychoanalytic works developed in Europe starting on 1950 decade about the observation and intervention of the mother and baby relationship had influence in Brazil, withal the last decades. This work had the purpose to comprehend the repercussion that different psychoanalytic models dedicated to observation and the intervention of dad-baby relationship exercised with the Brazilian psychoanalysis. Based on a historic method, a national articles production survey was made about observation and intervention of mother-baby relationship on Psi BVS database, on the past 2 decades. The results indicates the existence of 42 articles that was analyzed and delimitated in 4 principals categories: Epistemological theoretical studies, Esther Bick variations methods, Intervention practices on mother and baby relationship in expanded clinics and searches about the mother and baby relationship characteristics. Conclude that the works about the mother-baby relationship developed in Europe had repercussion on the Brazilian psychoanalyze, influencing, withal, institutional searches and practices in different contexts.
\end{abstract}

Keywords: psychoanalysis, mother-baby relationship, history, intervention, observation. 
Os primeiros trabalhos de observação e intervenção da relação mãe e bebê surgiram de forma efetiva na da década de 1940 e 1950, período pós segunda Guerra mundial, tendo como pioneiros dessa prática John Bowlby (1969), Melanie Klein (1952), Donald Winnicott (1941) e Anna Freud (1953), entre outros.

No Brasil, o nascimento da clínica psicanalítica com bebês se da junto ao contexto da difusão da psicanálise de crianças, por meio do espaço propício para a introdução de ideias relativas à observação de bebês estruturada por Esther Bick, por intermédio da psicanalista Lygia Amaral, no estado de São Paulo, e Rosa Beatriz Pontes de Miranda, no Rio de Janeiro. Esse movimento tem inicio na década de 1950 e é concretizado nas década 1960 e 1970 pela difusão e utilização de seu método em vários trabalhos em diferentes contextos clínicos. A partir da década de 1990, outros modelos teóricos capitaneados por diferentes autores na psicanálise, passaram a ser difundidos no Brasil.

Neste sentido, o presente trabalho tem por objetivo compreender, valendo-se de um vértice histórico, a repercussão e a influência que os diferentes modelos psicanalíticos dedicados a observação e intervenção da relação pais-bebê exerceram junto a psicanálise brasileira, nas últimas duas décadas, em periódicos nacionais.

\section{METODOLOGIA}

Desta forma, a presente pesquisa caracteriza-se, portanto como um estudo qualitativo relativo à história da psicanálise no Brasil, e para tal foi empregada como fundamentação metodológica o modelo de pesquisa denominado de "Estado da Arte". O levantamento da produção de artigos nacionais ocorreu na base de dados BVS Psi, sendo usando os seguintes descritores como referência: observação de bebês; relação pais e bebês; intervenção pais e bebês.

\section{RESULTADOS}

A pesquisa resultou na identificação de 42 artigos que foram cuidadosamente analisado, quantos as características do trabalho, referencial teórico adotado, autores citados, entre outros aspectos. A partir da análise delimitou-se 4 categorias, nas quais foram alocados: Estudos teóricos epistemológicos, Variações do método Esther Bick, Aplicação do observação mães e bebês em práticas institucionais e Pesquisas sobre características da relação mãe bebê.

A primeira categoria delimitada recebeu a denominação de "Pesquisas sobre características da relação mãe bebê", reunindo 23 trabalhos que tem em comum o objetivo de compreender determinadas características que interferem na relação mãe bebê. 
Nota-se portanto, que os trabalhos desta modalidade abordam diversas temáticas, contudo, todos, em maior ou menor grau, visam compreender como determinadas circunstâncias interferem ou afetam a relação mãe e bebê. Para tal, diferentes questões, tanto orgânicas como psíquicas da mãe e/ou da criança, são consideradas nestas investigações, no caso, aspectos da díade que compõem a relação.

A análise dos artigos apontam que tanto limitações ligadas ao contexto familiar, cultural, sócio econômico, assim como a existência de problemas orgânicos e psíquicos, tanto na família ou e no bebê, tem a propensão repercutir na interação da díade. Outro tema estudo é o fenômeno resultante de perturbações no vínculo afetivo, por diferentes motivos, tais como carência ou negligência de cuidados maternos, com o intuito de expandir o conhecimento dos efeitos psíquicos e funcionais no bebê.

Por fim, verificou-se, tanto pelo material levantado na pesquisa, quanto pela literatura, que trabalhos que examinam a relação entre conteúdos representados e comportamentos da interação da díade vem ganhando espaço de discussão e reflexão entre os estudiosos da relação mãe e bebê. Constata-se dessa forma que as pesquisas atuais concentram atenção nas repercussões da qualidade relação mãe bebê e em seu desenvolvimento posterior, devido ao seu caráter preventivo.

A segunda categoria foi intitulada "Variações do método Esther Bick" por ser composta por 5 trabalhos, que se apropriam deste determinando referencial teórico técnico, buscando desenvolvê-lo em diferentes contextos e práticas diversas, como atendimentos clínicos, pesquisas, utilização como método de ensino, entre outros.

Atualmente existe um grande número de profissionais que passaram a fazer uso desta técnica para outras finalidades após evidenciarem seu valor como instrumento de aprendizagem, pesquisa e clínica. Isto decorre da oportunidade a ele vinculada de se presenciar o desenvolvimento do bebê, sua constituição, e o desdobramento de sua relação no âmbito familiar, sobretudo com a mãe. Já outros trabalhos exploram a funcionalidade deste técnica como ferramenta clínica em função de seu caráter terapêutico, usando casos clínicos para esbouçar como um observador com um olhar continente pode realizar uma intervenção silenciosa e sutil, que favoreça o âmbito familiar.

Por meio dos artigos também encontramos autores que validam a aplicação da técnica de Bick para fins de pesquisa, em consequência do material obtido por meio desta prática e suas supervisões, que normalmente evidenciam questões possíveis de investigação científica. Ademais, está técnica vem sendo utilizada para coleta de dados em pesquisas sobre a primeira infância em 
diferentes ambientes como creches, instituições de abrigo, em setores hospitalares, e em contextos de vulnerabilidade.

Perante o material apresentado, espera-se ter transmitido o espaço criado e conquistado ao longo do tempo por esse referencial, diante de sua atual aplicação em outros tipos de setting como o da saúde, educação e social. Observa-se que sua utilização vai sendo adaptada, e os instrumentos definidos, de acordo com a instituição ou finalidade de sua utilização, sempre tendo como base os princípios básicos da observação de Bick.

A terceira categoria foi intitulada "Estudos teóricos epistemológicos" considerando o elemento comum entre os 8 artigos que a compõem, no caso, o foto de se dedicam a discussões relacionados a estudos conceituais, históricos e epistemológicos, concernentes as práticas psicanalíticas de observação e intervenção da relação mãe e bebê.

Outra questão relevante nesse grupo de artigos é o fato de se dividirem em diferentes áreas de reflexão, apesar da característica teórica comum a todos eles, podendo desta forma diferenciar dois pequenos grupos de interesses, quais sejam: perspectivas teóricas da interação pais bebê e fatores de risco para a relação mãe e bebê.

O primeiro grupo pode ser designado como trabalhos que têm como foco abranger diferentes perspectivas teóricas e metodológicas da interação pais-mães-bebês, fazendo uso, no entanto, de diferentes métodos para realizar tal objetivo. Tais trabalhos têm em comum o fato de terem sido realizados no inicio do ano 2000 e de terem se delimitado a agrupar informações a respeito deste tema referentes a décadas de 1970, 1980, e 1990.

É possível supor que no início da década de 2000 já existia um conjunto de trabalhos e pesquisas sobre relação mãe-bebê desenvolvidos no Brasil, no curso das décadas anteriores, o que impulsionou o surgimento de trabalhos de revisão, seja no contexto nacional ou internacional.

De acordo com a pesquisa de Wendland (2001), esse período se evidencia pela quantidade de trabalhos em diferentes linhas teóricas, que passam a ocorrer, sobretudo pós Segunda Guerra Mundial, tendo como precursores os trabalhos de linha psicanalítica, principalmente de Bowlby. Desta forma, os trabalhos psicanalíticos foram os pioneiros neste módulo de estudo, oferecendo subsídios para fomentar de diferentes temas de pesquisas a respeito da díade mãe e bebê, sendo que, atualmente as três perspectivas teóricas principais empregadas nas pesquisas e intervenções relativas à relação mãe-bebê são: a psicanalítica, a etológico-evolucionária da teoria do apego; e a sócio-histórica ou sociocultural.

A segunda subcategoria é constituída por trabalhos que, por meio de uma revisão bibliográfica, estudam questões que colocam o risco à qualidade da relação mãe e bebê devido a 
causas orgânicas, no caso dos artigos dessa subcategoria, malformação e deficiência visual e autismo, sendo portanto denominada fatores de risco para a relação mãe e bebê.

Por meio dos pontos aqui articulados nesta categoria, algumas conclusões podem ser concebidas. $\mathrm{O}$ foco de estudo em relação aos componentes da díade mãe e bebê aparentam estar passando por uma transição de interesse, partindo primeiramente de focos interacionais para atualmente se concentrar em aspectos diversos da relação. Este fato pode ser ilustrado pela divisão ocorrida entre os artigos desta modalidade de acordo com o ano e tema.

Denominada de "Práticas de intervenção na relação mãe bebê na clínica ampliada" nossa quarta e última categoria é constituída por 5 artigos que buscam discutir diferentes modalidades de aplicação em contextos institucionais diversos. Entretanto, esse contingente de trabalhos merece destaque por representar a ampliação clínica das práticas de intervenção na relação mãe e bebê, ou seja, está modalidade corresponde ao desenvolvimento da técnica psicanalíticas com bebês.

Atualmente está modalidade vem sendo denominada de clínica psicanalítica ampliada, e como sua característica temos a ampliação das possibilidades de escuta para um setting considerado coletivo, buscando a elaboração de estratégias a partir da identificação das motivações e demandas da sociedade por um acolhimento clínico. Desta forma, as instituições propiciam um local no qual o sujeito tem a oportunidade de ser acolhido através do manejo da transferência e do espaço de fala e escuta, representando a amplificação de uma clínica individual para coletiva.

Em relação a clínica psicanalítica com bebês, pode-se encontrar trabalhos atuais em diferentes contextos, como casas abrigo, creches, hospitais, entre outros. Isto devido a profissionais que voltaram seu olhar para necessidade desses menores, buscando compreender os efeitos destes espaços, tanto para e bebê, quanto para a relação da díade, e intervir quando necessário.

Neste sentido, os artigos que compõem essa categoria vem ilustrar essa ampliação por meio do atendimento psicanalíticos em outras instituições, como hospitais, UTI. Ademais, também nessa categoria se encontram trabalhos que buscam validar as consultas terapêuticas para intervenções nas relações iniciais pais bebês nesse novos espaço de atendimentos.

Atenta-se que esses trabalhos foram realizados nos últimos anos, representando o movimento de se ampliar as possibilidades de escuta e acolhimento para outros locais além do setting tradicional. Esta características pode estar a serviço primeiramente de um maior conhecimento a respeito do funcionamento das relações iniciais e seus efeitos colaterais, devido 
as pesquisas ocorridas nas décadas 1980 e 1990, destacando por meio destes resultados a necessidade de estender $\mathrm{o}$ atendimento a comunidade.

\section{DISCUSSÃO E CONCLUSÃO}

Fundamentado no material analisado percebe-se que os estudos psicanalíticos referentes a relação mãe e bebê têm ganhado maior proporção a partir da década de 2000, em relação as décadas anteriores, assim como uma maior dimensão acerca dos fenômenos envolvidos na relação mãe e bebê. $\mathrm{O}$ aumento de estudos nesta área, assim como os temas estudados, estão correlacionados, e tem um comum o fato de representarem a expansão deste campo de estudo.

As pesquisas iniciais, sobretudo as iniciados no período pós Segunda Guerra Mundial, deram bases e ferramentas para auxiliar as pesquisas posteriores. As pesquisas ocorrido na década de 1950 e 1960, serviram para lançar o olhar dos pesquisadores para este fenômeno, e as respostas encontradas contribuíram para uma melhor compreensão ao mesmo tempo que trazia novas indagações acerca de outros aspectos da relação da díade. Deve-se considerar também que a escolha pelos temas pesquisados sofrem influência de circunstâncias históricas e mudanças sociais, fato claramente ilustrado pelo contexto de pós-guerra o qual deu inicio a pesquisas como de Anna Freud, Bowlby, entre outros.

No momento atual, sabe-se que as pesquisas ocorridas nas década de 1980, 1990 chegaram ao resultado de que as representações maternas acerca de bebê constituem um elemento potencializador ou limitador para o desenvolvimento posterior da criança, e de que a partir dos primeiros contatos e interações entre a mãe e seu bebê, futuras perturbações podem ocorrer para o estabelecimento do vínculo materno, assim dificuldades para a relação subsequente. Isto posto, passamos nesse momento por um período de integração das perspectivas e conhecimentos adquiridos sobre a relação mãe e bebê no longo das ultimas décadas.

Constata-se assim que os estudos atuais tem como prioridade a repercussão da qualidade da relação mãe e bebê em seu desenvolvimento posterior, em relação aos estudos voltados para questões metodológicas e divergências teóricas.

Referente ao desenvolvimento da técnica psicanalítica na clínica mãe e bebê torna-se necessário mencionar que os artigos confirmam as indagações iniciais acerca dos desdobramento dos modelos psicanalíticos Europeu em nosso continente. As práticas clínicas ainda hoje se mantém forte no âmbito do consultório clinico, entretanto, se expandindo para novos espaços. 
Nesta pesquisa se destacaram trabalhos ocorridos no contexto hospitalar, em diferentes setores nesse âmbito, e em casas abrigo. Esses trabalhos, além de fazerem uso dos princípios psicanalíticos em modo geral, demonstra basear sobretudo nas ideias de Esther Bick, Crammer e Palacio-Espasa e Winnicott, os utilizando para ampliar as possibilidades de escuta e acolhimento em diferentes locais e situações, construindo condutas singulares de acordo com a demanda e necessidade.

Em vista do crescimento e o desenvolvimento teórico e técnico deste fenômeno, torna-se impossível exaurir a grande diversidade de contribuições dos estudos envolvidos com este tema, sendo este portanto um campo relevante de estudo tanto para questões acadêmicas como práticas.

\section{REFERÊNCIAS}

BOWLBY, J. Attachment and loss. Vol 1. New York: Basic Books. 1969.

FREUD, A. Children observation and prediction of development. Psychoanalytic Study of the Child, v. 13, n. 2,1958 . p. 123-124.

FREUD, A. Some remarks on infant observation. Psychoanalytic Study of the Child, v. 8, n. 1, 1953. p. 9-19.

KLEIN, M. Sobre a observação do comportamento de bebês. In Inveja e gratidão e outros trabalhos. Rio de Janeiro: Imago, 1991. (Original publicado em 1952).

WENDLAND, J. A abordagem clínica das interações pais-bebê: Perspectiva teóricas e metadológicas. Psicologia: Reflexão e Crítica , v. 14, n. 1, p. 2001. 45-56.

WINNICOTT, D. A observação de bebês em uma situação estabelecida. In Textos selecionados da pediatria à psicanálise. Rio de Janeiro: Francisco Alves, 1988. P. 491 - 498. (Original publicado em 1941) 